\title{
ONCHOCERCA DEWITTEI JAPONICA N. SUBSP., A COMMON PARASITE FROM WILD BOAR IN KYUSHU ISLAND, JAPAN
}

\author{
UNI S.*, BAIN O.**, TAKAOKA H.***, MIYASHITA M.* \& SUZUKI Y.****
}

\section{Summary :}

We describe Onchocerca dewittei japonica n. subsp. from the Japanese wild boar, Sus scrofa leucomystax, in Oita, Kyushu Island, where all seven animals examined were found to be infected. This study began with efforts to identify the causative species in a recent case of zoonotic onchocerciasis. Compared with Onchocerca dewittei dewittei from Sus scrofa jubatus in Malaysia, which was reexamined here, our new subspecies has much greater space between the ridges on the females. In addition, its microfilariae (from uteri) are shorter (192-210 $\mu \mathrm{m}$ compared with 228-247 $\mu \mathrm{m})$, and only the posterior third of the microfilarial body is coiled, instead of the entire body. The Onchocerca species parasitic in suids (these two subspecies and O. ramachandrini from the warthog in the Ethiopian region) form a group sharing several characters. Among the most unusual characters are the body swellings/a specialized apparatus for mating, known in only a few other genera). In addition, longitudinal cuticular crests were found on males of both subspecies from wild boar and on females of $O$. ramachandrini.

KEY WORDS : nematodes, filaria, Onchocerca, wild boar, Suidae, Japan.
Résumé : ONCHOCERCA DEWTTTEI JAPONICA N. SUBSP., UN PARASITE COMMUN CHEZ LE SANGLier, DANS L'îLE DE KYUSHU AU JAPON

Description d'une onchocerque $\bigcirc$. dewittei japonica n. subsp. qui s'avère très fréquente chez le sanglier Sus scrofa leucomystax, à Oita, Kyushu Island. Elle est distincte d'O. dewittei dewittei, parasite de S. scrofa jubatus en Malalsie (réétudié ici) par les côtes transversales de la cuticule de la femelle beaucoup plus espacées, la microfilaire un peu plus petite (192-210 au lieu de 228-247 um, dans l'utérus) et au corps enroulé seulement dans le tiers postérieur (au lieu du corps entier). Les onchocerques des suidés, $\bigcirc$. dewittei japonica, $\bigcirc$. dewittei dewittei et, en région éthiopienne chez le phacochère $\bigcirc$. ramachandrini, forment un petit groupe particulier avec, entre autres, deux traits originaux: les renflements dans la région antérieure du corps /considérés comme un appareil favorisant l'accouplement, observé seulement dans quelques rares autres genres de filaires), les petites crêtes longitudinales sur la cuticule des mâles des deux sous-espèces et sur la femelle $d^{\prime} O$. ramachandrini.

MOTS CLÉS : nématodes, filaire, Onchocerca, sanglier, Suidae, Japon.

\section{INTRODUCTION}

T

n Oita, Kyushu Island, Japan, three Onchocerca species, all from ruminants, are transmitted by 1 Simulium species (Takaoka \& Bain, 1990; Takaoka, 1994): two are cosmopolitan, O. gutturosa Neumann, 1910 and O. lienalis (Stiles, 1892), and one, O. suzukii Yagi, Bain \& Shoho, 1994, is a parasite of the Japanese serow, and in this region, is a transfuge in cattle (Uni et al., 1998).

* Department of Medical School, Osaka City University Medical School, Osaka 545-8585, Japan.

** Institut de Systématique, CNRS FR 1543, Muséum National d'Histoire Naturelle et Ecole Pratique des Hautes Etudes, Parasitologie Comparée et Modèles expérimentaux, 75231 Paris, Cedex 05, France. *** Department of Infectious Disease Control, Oita Medical University, Oita 879-5593, Japan.

**** Laboratory of Veterinary Anatomy, Faculty of Agriculture, Gifu University, Gifu 501-1193, Japan.

Correspondence: S. Uni, Department of Medical Zoology, Osaka City University Medical School, 1-4-3 Asahimachi, Abeno-ku, Osaka 5458585, Japan.

Tel.: +81-6-6645-3760 - Fax: +81-6-6645-3762.

E-mail: uni@med.osaka-cu.ac.jp
The worm found in a recent case of zoonosis (Takaoka et al., 2001) was not identifiable as any of these species, but resembled a parasite from a suid in Malaysia, O. dewittei Bain, Ramachandran, Petter \& Mak, 1977. The resemblance prompted us to search for this parasite in wild boar in Oita. Onchocerca specimens were recovered; the Japanese material, although very similar morphologically to the Malaysian species, had constant distinctive characters, and we describe it here as a new subspecies.

\section{MATERIALS AND METHODS}

S even Japanese wild boar, Sus scrofa leucomystax, in Oita, Kyushu Island, were killed between November 1999 and November 2000, in accordance with policies concerning the conservation of wild animals in Japan. Animals were refrigerated for a few days and skin snips were made from the ears, eyes, limbs, back, and tail. Adult filarial parasites were searched for by dissection of material that had been stored in a refrigerator or freezer. The adult parasites recovered were stored in $2 \%$ formalin in saline, and 
microfilariae were extracted from the ovijector of female worms for morphologic study. The caudal papillae of the males were numbered as in Chabaud \& Petter (1961).

O. dewittei, from Sus scrofa jubatus in Malaysia, was reexamined [one male, and female fragments including one anterior extremity and two posterior extremities; type material, Muséum National d'Histoire naturelle (MNHN), Paris collection, $\mathrm{N}^{\circ} 100 \mathrm{EJ}$; two slides of stained skin microfilariae, $\mathrm{N}^{\circ} 50 \mathrm{EJJ}$.

Drawing of the parasites, histologic sections stained with hematoxylin-eosin or periodic acid Schiff (PAS), and scanning electron microscopy (SEM; Hitachi S4700) was done as described elsewhere (Uni et al. 1998).

\section{RESULTS}

B oth adult worms and microfilariae were found in all seven Japanese wild boar, showing a very high transmission rate. Adult worms were in nodular fibrous structures in the subcutaneous connective tissue of the distal part of the limbs or in clusters in the adipose tissue of footpads. Most microfilariae were found in skin snips of ears, back, and tail, and some were found in the skin of limbs. The authors' names of the subspecies described below are Uni, Bain \& Takaoka.

\section{ONCHOCERCA DEWITTEI JAPONICA}

UNI, BAIN \& TAKAOKA, N. SUBSP.

(Figs. 1-2, 4-9)

Specimens: female holotype (B2-23), male allotype (B2-29), No 256 HS, Muséum National d'Histoire naturelle (MNHN), Paris. Paratypes: one female, two anterior and two posterior parts of females ( $\mathrm{N}^{\circ} 257 \mathrm{HS}$ ). Other specimens: one female, two anterior parts of females, and one male ( $\mathrm{N}^{\circ} 258,262 \mathrm{HS}$ ), in MNHN collection, Paris. Twelve paratypes and 20 specimens other than paratypes in the Department of Medical Zoology, Osaka City University Medical School.

Type host: Sus scrofa leucomystax Temminck (Suidae).

Location in host: connective and adipose tissues of distal part of limbs and footpads.

Type locality: Mt. Sobo, Oita Prefecture, Kyushu, Japan.

- Female (one complete specimen, 30 anterior and 22 posterior parts)

External-labial papillae arranged in a rectangle elongated dorsoventrally, and cephalic papillae arranged in a square (Fig. 4). Thin elongated and undivided esophagus. Vulva at the mid-length or posterior half of esophagus (Fig. 1B).
Cuticle: thick, sharp, and straight ridges with wide spacings in the main part of the body; ridges interrupted in lateral field, and not furcated, a few overlapping (Fig. $1 \mathrm{~F}$ and $1 \mathrm{H}$ ). In anterior region, approximately 1.5 to $6 \mathrm{~mm}$ from apex, small bosses; less anteriorly, ridges present but condensed, becoming gradually more distant and thicker (about $100 \mu \mathrm{m}$ apart and $15 \mu \mathrm{m}$ high at $12 \mathrm{~mm}$ from apex, Fig. 1A). Near tail, ridges increasingly closer and thinner.

Four body swellings in the first $10 \mathrm{~cm}$ in a complete female. Large pseudocoelomocyte spread in body cavity at the level of a body swelling (Fig. 1G and Fig. 5). Forty to 66 muscle cells found in cross-sections at midbody.

Tail curved dorsally; extremity smooth but with internal terminal point. Subterminal elongated phasmids.

- Microfilariae

In the uterus of female worms and skin of host animals; generally coiled posterior region, this part never exceeding one third of body; rarely, only the tail curved (Fig. 2, M-1-3).

- Male (three complete males, six anterior parts, and five posterior parts)

Four body swellings in the anterior part (Fig. 2N). Cuticular ornamentation: tiny longitudinal crests or bosses (Fig. 2O); about 130 counted on a body cross-section; with SEM, crests 2.5 to $5.0 \mu \mathrm{m}$ long and $2.5 \mu \mathrm{m}$ apart (Figs. 8-9).

Nine to ten pairs of caudal papillae arranged in two groups. Near cloacal aperture, two large precloacal pairs and one small paracloacal pair (probably pairs 2, 3 , and 4), one sub-ventral small pair and one lateral large post-cloacal pair (5 and 6, respectively); the number and position of papillae may vary (Fig. 2Q-R). In posterior half of tail, four aligned pairs ( 7 to 10); phasmids near pair 10. Extremity of tail with one or two knobs beneath cuticle.

- Measurements

Female holotype (extreme values of paratypes and other specimens): body 273 (167) $\mathrm{mm}$ long, 260 (190) $\mu \mathrm{m}$ wide at midbody, nerve ring $230(170) \mu \mathrm{m}$ from anterior end, esophagus 1,200 (1,000-1,080) $\mu \mathrm{m}$ long, vulva 780 (400-630) $\mu \mathrm{m}$ from anterior end, ovijector $12,300 \mu \mathrm{m}$ long $(6,200-11,500)$, tail 160 (100-170) $\mu \mathrm{m}$ long and 100 (70-120) $\mu \mathrm{m}$ wide at anus. At midbody, ridges 220-250 (200; 140 in a thin young female) $\mu \mathrm{m}$ apart and $25-35 \mu \mathrm{m}$ thick, cuticle $20 \mu \mathrm{m}$ thick. Body swellings 18 (8.5-14.5), 45, 105, and $120 \mathrm{~mm}$ from anterior end.

Microfilariae: from a paratype female worm: mean length $204 \mu \mathrm{m}$ (individuals: 192, 200, 203, 205, 208, 210, and $210 \mu \mathrm{m}), 6-7 \mu \mathrm{m}$ wide. From skin: mean length $197 \mu \mathrm{m}$ (individuals: 183, 190, 200, 200, 200, 200 , and $208 \mu \mathrm{m}$ ), 5-8 $\mu \mathrm{m}$ wide. 

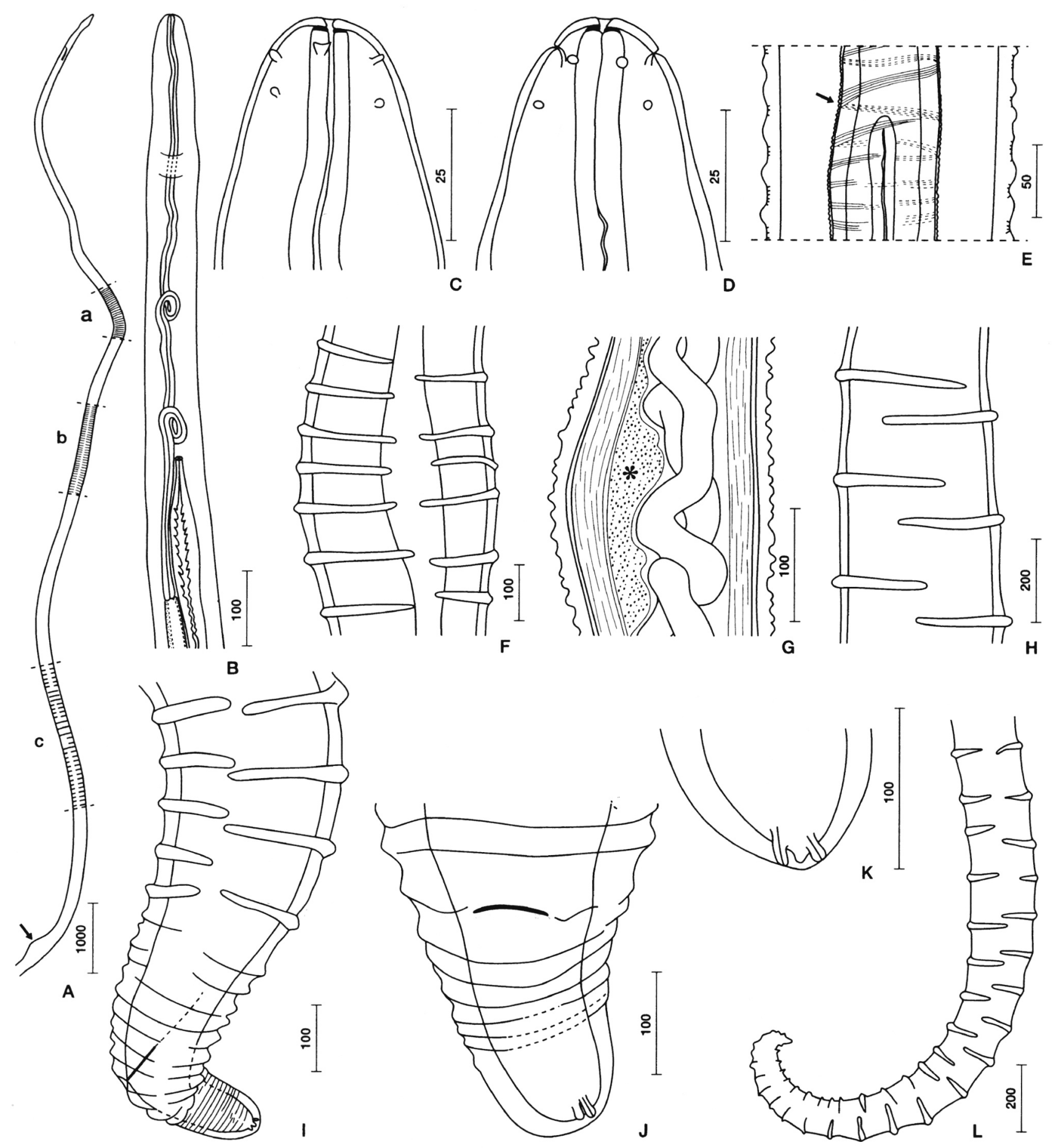

Fig. 1. - Onchocerca dewittei japonica n. subsp. A-L, females. A. Anterior part with varied spacing of transverse ridges and the first body swelling; a. condensed fine striations; b. transverse ridges with narrow spacing, and c. transverse ridges with wider spacing. Body swelling (arrow). B. Anterior part with vulva, ventral view. C. Head, lateral view. D. Head, median view. E. Posterior end of ovijector with two uteri, and their muscle fibers (arrow). F. First body swelling, lateral view. G. Pseudocoelomocyte $\left(^{*}\right)$ at body swelling. H. Transverse ridges at midbody, overlapping in lateral field. I. Posterior part, lateral view. J. Posterior part, ventral view. K. Tail extremity with internal knob and phasmids. L. Posterior part of a thin worm. Bars, micrometers. 

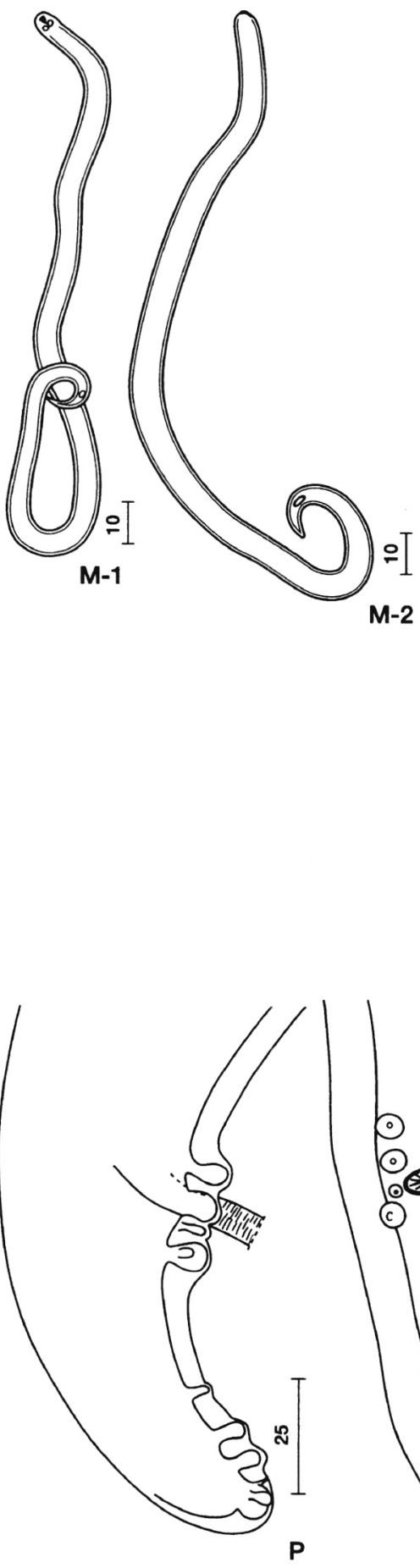

$\mathbf{P}$
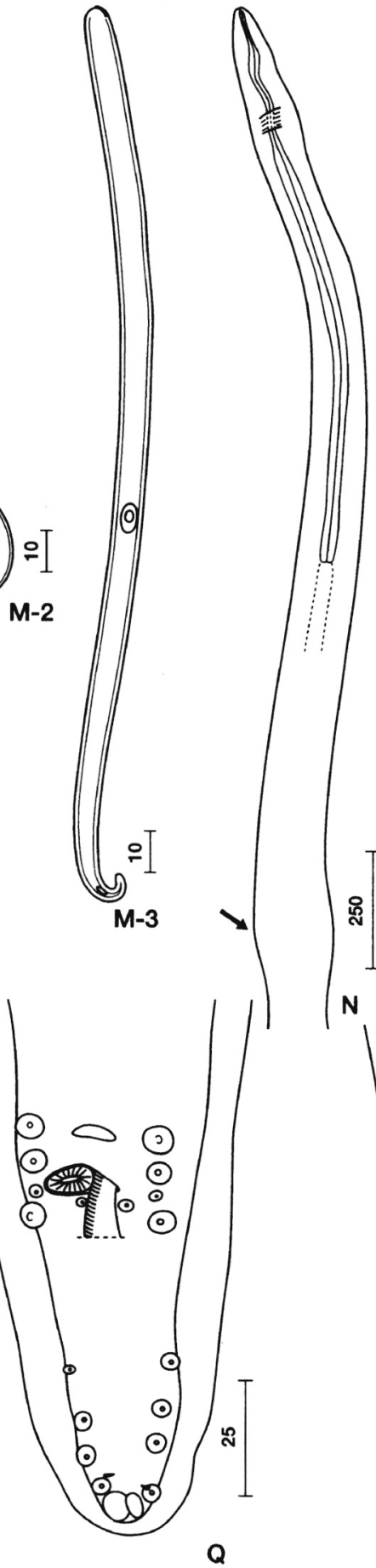

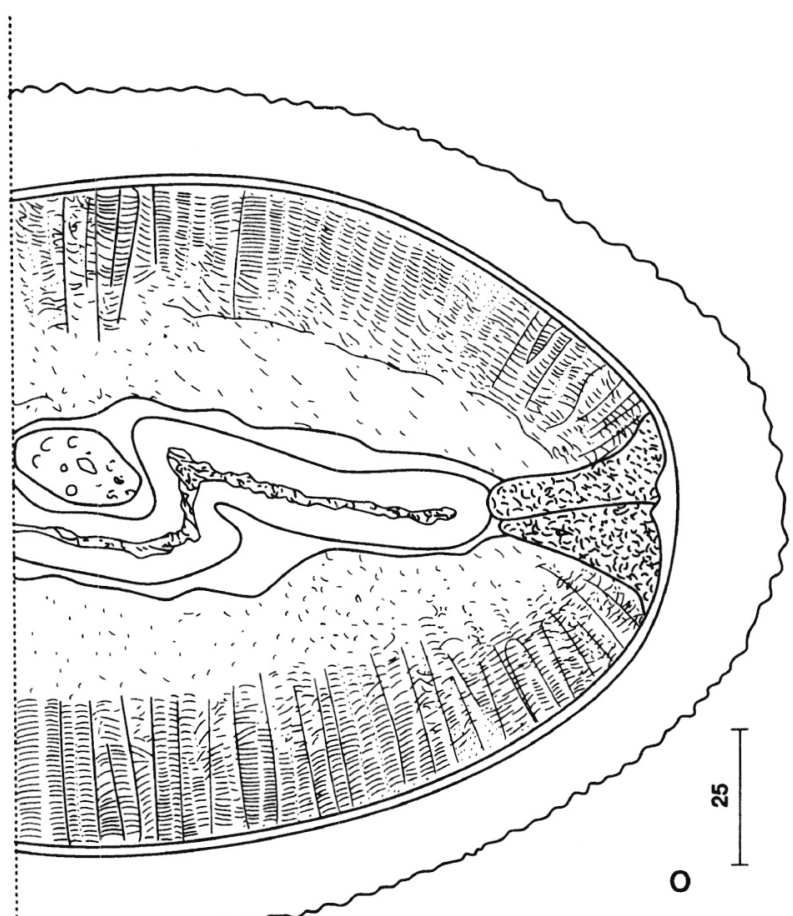

Fig. 2. - O. dewittei japonica n. subsp. M-1-3, Microfilariae from uteri. N-U, Males. N. Anterior part with body swelling (arrow). O. Crosssection at midbody. P. Tail, lateral view. Q. Idem, ventral view. R. Idem, another specimen, ventral view. S. Right spicule, ventral view, T. Left spicule, ventral view. U. Left spicule, lateral view. Bars, micrometers. 


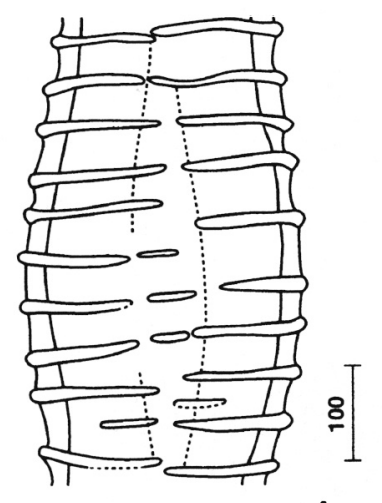

A
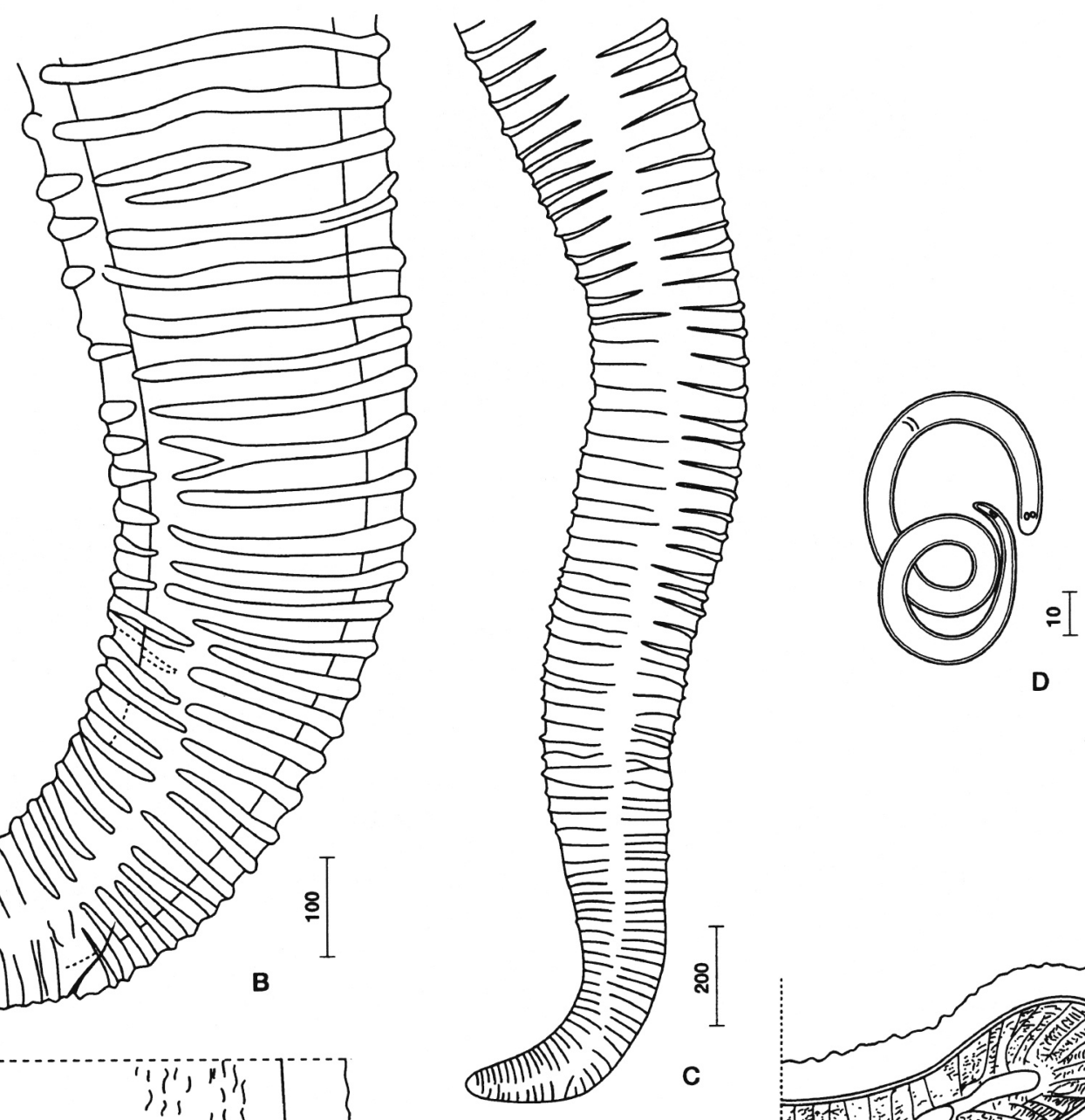

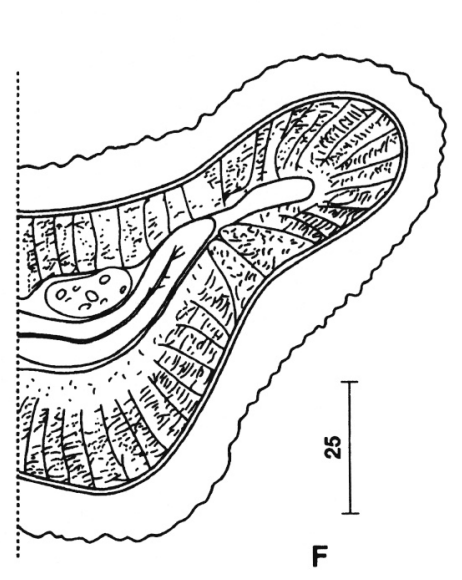

E

Fig. 3. - O. dewittei dewittei. A-C. Females. A. Body swelling, lateral view. B. Posterior part, lateral view. C. Same specimen, lower magnification. D. Microfilaria from skin. E. Cuticular crests of male at midbody, ventral view. F. Cross-section at midbody of a male. Bars, micrometers. 

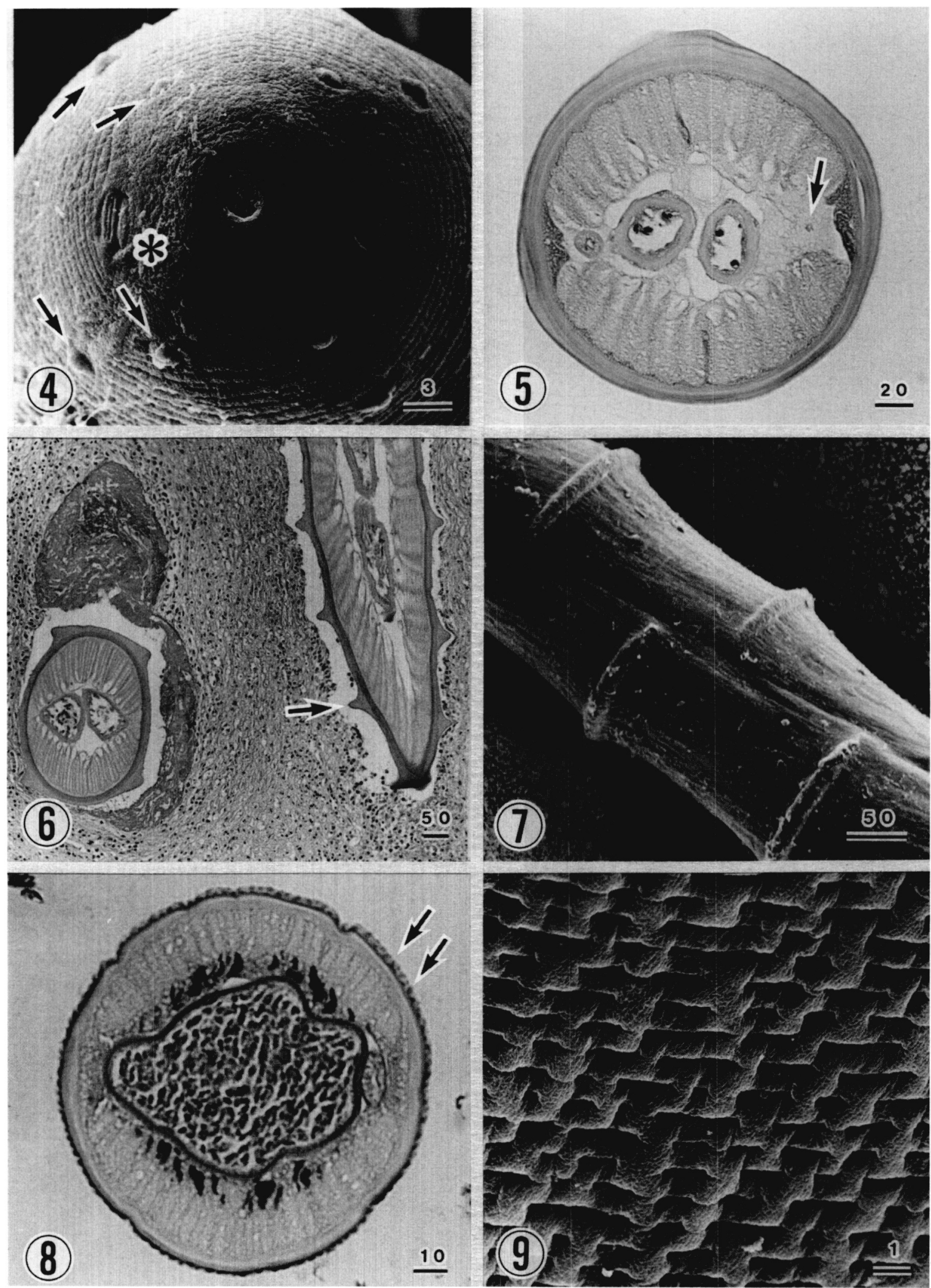

Figs. 4-7. - Females of $O$. dewittei japonica n. subsp. Fig. 4. SEM of en face view of head. Papillae (arrows) and amphid (*). Fig. 5. Crosssection at body swelling with a part of a pseudocoelomocyte seen on right (arrow indicates nucleus). Fig. 6. Histologic section of a female worm in a nodule, sharp ridge (arrow). Fig. 7. SEM of transverse ridges at midbody. Lateral view. Bar, micrometers.

Figs. 8 and 9. - Males of O. dewittei japonica n. subsp. Fig. 8. Cross-section of midbody. Cuticular crests (arrows). PAS stain. Fig. 9. SEM of cuticular crests. Bars, micrometers. 
Male allotype (another male): body 51 (54) mm long, 145 (130) $\mu \mathrm{m}$ wide at midbody; nerve ring 230 (230) $\mu \mathrm{m}$ from anterior end; esophagus $1,120(1,150) \mu \mathrm{m}$ long; tail 85 (90) $\mu \mathrm{m}$ long; right spicule 85 (88) $\mu \mathrm{m}$ long; left spicule 245 (250) $\mu \mathrm{m}$ long, with handle 120 (120) $\mu \mathrm{m}$ long. Four body swellings, 2, 8, 27, and $33 \mathrm{~mm}$ from anterior end.

\section{SUPPLEMENT FOR ONCHOCERCA DEWITTEI DEWTTTEI Bain, Ramachandran, Petter \& MaK, 1977 (Fig. 3)}

Body swellings present in female; their number not certain for broken specimens, but the first at $12.5 \mathrm{~mm}$ from apex. Tiny cuticular longitudinal crests or bosses (light microscopy and SEM; photographs are not shown) in male, similar to those of the Japanese specimens.

The constancy of some characters was confirmed: distance between two ridges not exceeding $120 \mu \mathrm{m}$ at midbody, ridges on the lateral field sometimes bifurcated, or short segments of ridge (Fig. 3A-B); whole body of microfilariae coiled in uterus (females fixed in hot $70 \%$ alcohol) and skin (hemalum-eosin staining or lactophenol, Fig. 3D).

\section{DISCUSSION}

$\mathrm{T}$ The Onchocerca specimens from S. scrofa leucomystax in Japan resemble those from S. scrofa jubatus in Malaysia. However, the Japanese specimens are distinguished by a few constant characters of the female cuticle and the microfilaria. In the female, the distance between adjacent ridges is two- to threefold that for the Malaysian species in the main part of the body and in the posterior region; the microfilaria is a little shorter than that of the other species (192$210 \mu \mathrm{m}$ compared with $228-247 \mu \mathrm{m}$ when extracted from uteri of fixed females), and the coiled part does not involve more than the posterior third of body. These characters have much significance for differentiation between Onchocerca species. Females in the genus Onchocerca have specialized cuticular architecture, probably because these extremely long worms have to resist pressure from elastic tissues such as tendons surrounding them. Microfilariae in Onchocercidae show signs of speciation more rapidly than adults (Bain, 1968). The differences in habitus including shape are probably related to their different microniches in the arborization of the lymphatic and blood circulatory systems (Petit, 1985). We concluded that the Japanese material described here is a subspecies of $O$. dewittei, which we name $O$. dewittei japonica $n$. subsp.

We suggested previously that the Onchocerca species parasitic in suids, O. dewittei dewittei in Asia and
O. ramachandrini Bain, Wahl \& Renz, 1993 from the warthog in Africa, are closely related morphologically (Bain et al., 1993). Findings reported here were consistent with that suggestion. The body swellings, a specialized apparatus for mating, are known in only a few filarial genera such as Mansonella and Cercopithifilaria (Bain \& Chabaud, 1988; Uni et al., 2001). In Onchocerca species, the swellings have been found so far only in these parasites from suids. Longitudinal crests are present on the cuticle of males of both subspecies and females of O. ramachandrini (Bain et al., 1993). The habitats of boar and humans overlap in rural areas in Oita, Kyushu Island, so the high prevalence of this Onchocerca species in wild boar may lead to zoonotic onchocerciasis (Takaoka et al., 2001).

\section{ACKNOWLEDGEMENTS}

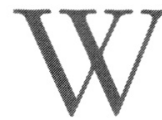
e thank Professor J. Baker for advice about the English of the manuscript. This study was supported by a grant (No. 10306020) from the Ministry of Education, Science, Sports, and Culture, Japan.

\section{REFERENCES}

Bain O. Remarques au sujet d'une nouvelle Filaire de Caméléon malgache, proche de F. brevicaudata. Bulletin $d u$ Muséum national d'Histoire naturelle, 1968, 40, 802-806.

Bain O. \& Chabaud A.G. Un appareil favorisant l'accouplement des Filaires : les renflements de la région antérieure du corps. Annales de Parasitologie Humaine et Comparée, 1988, 63, 376-379.

Bain O., Ramachandran C.P., Petter F. \& MaK J.W. Description d'Onchocerca dewittei n. sp. (Filarioidea) chez Sus scrofa en Malaisie. Annales de Parasitologie Humaine et Comparée, 1977, 52, 471-479.

BAIN O., WAHL G. \& RENZ A. Onchocerca ramachandrini n. sp. from the warthog in Cameroon. Annales de Parasitologie Humaine et Comparée, 1993, 68, 139-143.

Chabaud A.G. \& Petter A.J. Remarques sur l'évolution des papilles cloacales chez les Nématodes phasmidiens parasites de Vertébrés. Parassitologia, 1961, 3, 51-70.

PETIT G. Ingestion des hématozoaires par le vecteur. Analyse de quatre filaires parasites d'un Saïmiri. Annales de Parasitologie Humaine et Comparée, 1985, 60, 247-297.

TAKAOKA $H$. Natural vectors of three bovine Onchocerca species (Nematoda: Onchocercidae) and seasonal transmission by three blackfly species (Diptera: Simuliidae) in central Kyushu, Japan. Journal of Medical Entomology, 1994, 37, 404-416.

TAKaOKa H. \& Bain O. Infections of blackflies (Diptera: Simuliidae) with three types of zoonotic Onchocerca larvae in Oita, Japan. Japanese Journal of Tropical Medicine and Hygiene, 1990, 18, 1-10. 
Takaoka H., Bain O., Uni S., Korenaga M., Tada K., Ichikawa H., Otsuka Y. \& Eshita Y. Human infection with Onchocerca dewittei japonica, a parasite from wild boar in Oita, Japan. Parasite, 2001, 8, 261-263.

Uni S., Suzuki Y., Baba M., Mitani N., Takaoka H., Katsumi A. \& BaIN O. Coexistence of five Cercopithifilaria species in the Japanese rupicaprine bovid, Capricornis crispus. Parasite, 2001, 8, 197-213.

Uni S., Suzuki Y., Chiba H., Katsumi A., TakaOka H. \& Bain O. An Onchocerca species from cattle on Kyushu Island is O. suzukii, a transfuge parasite from the Japanese endemic bovid, Capricornis crispus. Japanese Journal of Tropical Medicine and Hygiene, 1998, 26, 157-160.

Uni S., Suzuki S. \& Katsumi A. Cercopithifilaira shohoi n. sp. (Nematoda: Filarioidea) from the relict Bovidae, Capricornis crispus, in Japan. Parasite, 1998, 5, 119-126.

Reçu le 14 décembre 2000 accepté le 14 juin 2001 